\title{
Hā Ora: Reflecting on a Kaupapa Māori Community-Engaged Co-design Approach to Lung Cancer Research
}

\author{
Jacquie Kidd, Shemana Cassim, Anna Rolleston, Rawiri Keenan, Ross Lawrenson, Nicolette \\ Sheridan, Isaac Warbrick, Janette Ngaheu, Brendan Hokowhitu
}

A R T I C L E IN F O

Keywords:

Community engagement

Indigenous

Rural communities

Health inequities

Māori

Kaupapa Māori

Lung cancer

Early diagnosis

https://doi.org/10.32799/ijih.v16i2.33106

\author{
A B S T R A C T
}

\section{A UTHOR INFO}

Co-designed research is gaining prominence within the health care space. Community engagement is a key premise of co-design and is also particularly vital when carrying out kaupapa Māori research. Kaupapa Māori describes a "by Māori, for Māori” approach to research in Aotearoa/New Zealand. This article discusses the research process of Hā Ora: a co-design project underpinned by a kaupapa Māori approach. The objective was to explore the barriers to early presentation and diagnosis of lung cancer, barriers identified by Māori. The team worked with four rural Māori communities, with whom we aimed to co-design local interventions that would promote earlier diagnosis of lung cancer. This article highlights and unpacks the complexities of carrying out communityengaged co-design with Māori who live in rural communities. In particular, we draw attention to the importance of flexibility and adaptability in the research process. We highlight issues pertaining to timelines and budgets, and also the intricacies of involving co-governance and advisory groups. Overall, through this article, we argue that health researchers need to prioritise working with and for participants, rather than on them, especially when working with Māori communities.

Jacquie Kidd, Faculty of Environmental and Health Sciences, Auckland University of Technology, Private Bag 92006, Auckland 1142, New Zealand. Email: jacquie.kidd@aut.ac.nz

Shemana Cassim, Waikato Medical Research Centre, University of Waikato, Hamilton, New Zealand

Anna Rolleston, Te Huataki Waiora School of Health, University of Waikato

Rawiri Keenan, Waikato Medical Research Centre, University of Waikato

Ross Lawrenson, Waikato Medical Research Centre, University of Waikato

Nicolette Sheridan, School of Nursing, Massey University, Auckland, New Zealand

Isaac Warbrick, Taupua Waiora Research Centre, Auckland University of Technology

Janette Ngaheu, Midland Cancer Network, Hamilton, New Zealand

Brendan Hokowhitu, Te Pua Wānanga ki te Ao, Faculty of Māori and Indigenous Studies, University of Waikato 
Aotearoa: New Zealand

\section{Glossary}

hui: meeting or focus group

iwi: tribe

kai: food

kaiāwhina: healthcare advocate

kanohi-ki-te-kanohi: face-to-face

karakia: prayer

Kaumātua: respected Elder

kaupapa Māori: a Māori focus incorporating the knowledge, skills, attitudes and values of

Māori society

kawa: protocols

koha: gift of thanks

kōrero: story

korowai: traditional Māori cloak

mana: pride and status

Māori: Indigenous Peoples of New Zealand

marae: Māori meeting space

mihi: speech of greeting/introduction that usually includes the recitation of one's family origins

Pākehā: New Zealanders of European descent

pou pupuru orranga: a health care advocate and navigator

pōwhiri: welcoming ritual/ritual of encounter

tapu: sacred, prohibited, restricted, set apart, forbidden

te reo: the Māori language

Te Tiriti o Waitangi: the Treaty of Waitangi

tikanga: traditional protocols/customs

tino rangatiratanga: sovereignty and self-determination

waiata: song

whakaaro: thoughts/opinions

whakanoa: to remove tapu/restriction

whakawhanaungatanga: relationship building

whānau: family, generally related but also includes close social groups 


\section{Acknowledgements}

He tino honore mātou e whakanui ana mātou te kaupapa Hā Ora ki ngā iwi e whakatinana, e whakaora ai tēnei kaupapa à Hā Ora ki a rātou kōrerorero. Kā whakawhetai mätou ki ngà whānau e kōrero ana te kōrero e hìkoi ana te hīkoi ki tēnei huarahi, kahuri kia rātou hoki e wehi atu ki rangi whetu ma ki tua o te ārai ano kia rātou e ora tonu ai me ngā uri e heke mai nei, nōreira he honore ano $i$ a mātou ki te whakanui ènei rangatira me ā rātou whānau ki a whiri à rātou kōrero kia tau te rangimarie, te aroha me te whakapono Paimarire.
We are very honoured indeed to acknowledge those who shared their stories and brought to life Hã Ora. We are forever thankful and dedicate this to them, and also to their families for embracing Hā Ora. For talking the talk and walking the walk. To those who have passed on, who reside among the many stars of the heavens, to those living who remain with us, and for the generations to come. Again, it is indeed a great honour for us to acknowledge these rangatira and their families. May peace, love, and faith keep you safe. Paimarire.

The project discussed in this article was funded by the Health Research Council of New Zealand (HRC Grant 17/438, entitled "Improving Early Access to Lung Cancer Diagnosis for Māori and Rural Communities"). We are grateful for the collaboration of Hemi Curtis, Ngaroma Grant, Mariana Hudson, Mahina Joseph-Small, Shirley Keown, Bubsie McFarlane, Dallas Poi, Reweti Ropiha, Phyllis Tangitu, and Maryanne Thompson.

\section{Introduction}

Co-design is gaining prominence within the healthcare space as an approach to service design and delivery that may enable better uptake and outcomes because those impacted have been involved (Bate \& Robert, 2007). Ideally, the co-design process involves all stakeholders in the design process of a service, intervention, or other initiative as a way of ensuring that the results meet their needs. However, there is an increasing need to draw a distinction between community consultation versus community-driven engagement as the basis of co-design. To elaborate, project teams often carry out community consultation by capturing people's experiences regarding a particular issue, and designing a service or intervention that is then implemented in that community. A consultation approach does not reflect a genuine and effective partnership with communities (Bate \& Robert, 2007). Rather, the intention of co-design is community-driven engagement, where project teams work together with their stakeholders and/or community members to identify a problem that needs to be addressed, engage people, document their experiences relating to the problem, and then collectively devise a solution (Boyd 
et al., 2012; Rodgers, 2018). Similarly, a co-design approach involves researchers working in partnership with communities throughout a research process. As this article will demonstrate, such an approach to co-design enables the co-creation of interventions and ensures effective implementation, dissemination, uptake, and sustainability (Oetzel et al., 2017; Oetzel et al., 2015). Community-driven engagement is particularly vital when carrying out kaupapa Māori research.

Kaupapa Māori research describes a "by Māori, for Māori” approach to service and project development and implementation in Aotearoa New Zealand (Smith, 1999). Kaupapa Māori methodological approaches challenge the dominant narrative and associated power dynamics, so that Māori are not articulated as "the other" (Pihama, 2017). In particular, the undermining of Māori sociocultural, economic, and political structures through colonial processes has resulted in a redistribution of power and resources in favour of Pākehā (New Zealanders of European descent). This is reflected in the current economic, sociopolitical, and health inequities between Māori and Pākehā, alongside interventions aimed at addressing these inequities (Cormack et al., 2013; Harris et al., 2015). In Aotearoa, Te Tiriti o Waitangi is the founding document that underpins the relationship between the government and Māori. Te Tiriti guarantees tino rangatiratanga (sovereignty and self-determination) and the principles of mutual respect and the freedom to express tino rangatiratanga; active protection and being able to manage affairs according to tikanga (customary practice), including in mainstream health services; equity; and the right to choose people's own social and cultural path and exercise authority (Waitangi Tribunal, 2019). Te Tiriti o Waitangi has been poorly upheld in Aotearoa, but especially so in health (e.g., Waitangi Tribunal, 2019). The use of kaupapa Māori methodological approaches to improve Māori health outcomes is an avenue to redress this issue, and to meet obligations outlined within Te Tiriti. Interventions using kaupapa Māori approaches have been associated with improved health outcomes for Māori (Oetzel et al., 2017; Pitama et al., 2011; Tipene-Leach et al., 2013).

The current project, Hā Ora, is underpinned by a kaupapa Māori approach. Our core team comprised a Kaumātua (respected Māori Elder); two general practitioners (RL, who is of European descent, and RK, who identifies as Māori); two senior Māori academics (JK and AR), who were the cultural leads for Hā Ora; and a full-time research fellow (SC, who is an Indigenous researcher of Sri Lankan descent), alongside several other clinicians and researchers involved in an advisory capacity (both Māori and non-Māori). The objective was to explore the barriers to early presentation and diagnosis of lung cancer, as identified by Māori patients and whānau (family or close social group), particularly in primary care. We worked with four rural localities in Aotearoa which had relatively high lung cancer rates, aiming to co-design interventions that would promote earlier diagnosis of lung cancer.

This article will discuss the research process of this project to highlight and unpack the complexities and value of carrying out community-engaged co-design with Māori in rural communities. In addition to issues such as confidentiality and rigour, the ethics application for the project involved detailed information about consultation with Māori advisers, the use of 
Māori research approaches (detailed in this paper), and the inclusion of Māori researchers and collaborators throughout all stages of research and dissemination. Approval was received from the New Zealand Health and Disability Ethics Committee, reference number 17/STH/158.

\section{The Communities}

Four rural localities in the Midland region of the North Island of New Zealand were engaged. To ensure anonymity of the communities in these localities, they are identified as Community A, B, C, and D in this article. A brief profile of each community is presented below (See also Table 1 for a summary).

Community A was a small, relatively remote rural community, situated around 45 minutes away (by road) from the nearest rural hospital and 3.5 hours away from the nearest major regional hospital. The team worked closely with a Māori community-based health professional, an integral member of the community. This individual was a pivotal member in the Māori stakeholder group and was instrumental in organising community hui (meetings or focus groups) and getting the community members together to participate in the research.

Community B was also a small rural community, located an hour away from the nearest major regional hospital. While Community B also had its own rural hospital, many community members have to travel to the regional hospital regularly for (cancer) care and treatment. Community B had a relatively central location, being close to other rural towns, and therefore had access to the healthcare services of these towns. The team worked with two Māori stakeholders in this community who were active members in the healthcare space.

Community $\mathrm{C}$ was a larger rural community, with its own well-equipped hospital. This community was located 1.5 hours away from the nearest major regional hospital. Despite being considered a rural community on a national scale, this locality had a larger population compared

to the others that we worked with, and had a relatively central location with smaller neighbouring communities regularly accessing the hospital in Community C. In this community, the team worked with three prominent Māori activists in the healthcare and cancer spaces, who were key figures in supporting and promoting Māori health in general, and cancer care in particular.

Community D was also a larger rural community, with its own hospital. However, this community was very remote in its location, being a little over 5 hours away from the nearest major regional hospital. The stakeholder group in Community D comprised a Māori community organisation active in the healthcare space and important in supporting and promoting Māori health. While the team worked with this organisation as a whole, our regular correspondence was with two particular individuals within the organisation. 


\section{Table 1}

Summary of Community Profiles

\begin{tabular}{|l|l|l|l|}
\hline Community & Description & Distance to nearest hospital & $\begin{array}{l}\text { Number of stakeholders } \\
\text { engaged }\end{array}$ \\
\hline Community A & $\begin{array}{l}\text { Small, relatively } \\
\text { remote rural } \\
\text { community }\end{array}$ & $\begin{array}{l}45 \text { minutes from rural hospital, } \\
3.5 \text { hours from regional hospital }\end{array}$ & One individual \\
\hline Community B & $\begin{array}{l}\text { Small, rural } \\
\text { community }\end{array}$ & $\begin{array}{l}\text { Has its own rural hospital; 1 } \\
\text { hour away from regional } \\
\text { hospital }\end{array}$ & Two individuals \\
\hline Community C & $\begin{array}{l}\text { Larger rural } \\
\text { community }\end{array}$ & $\begin{array}{l}\text { Has well-equipped hospital; } \\
\text { regional hospital used for cancer } \\
\text { treatment (1.5 hours away) }\end{array}$ & Three individuals \\
\hline Community D & $\begin{array}{l}\text { Larger rural } \\
\text { community }\end{array}$ & $\begin{array}{l}\text { Has well-equipped hospital; } \\
\text { regional hospital used for cancer } \\
\text { treatment (5 hours away) }\end{array}$ & One organisation \\
\hline
\end{tabular}

\section{The Process(es): Community Engagement}

\section{Laying the Groundwork}

Initial engagement involved the members of the team approaching key contacts, Māori health teams in the local district health boards, or prominent individuals actively working within the healthcare space in each locality. Most of these connections were made prior to the funding application for the project being submitted, which was vital for the project to succeed. After the funding was received, members of the team met kanohi-ki-te-kanohi (face-to-face) with these individuals or groups primarily for whakawhanaungatanga (forming relationships and finding connections) and to also provide a background of the project and its aims. During these initial hui, the team asked these individuals if they would like to be part of this research project, if they would be happy for the project to include their locality, and to assist with organising the community hui, recruiting participants, and forming part of the team's broader stakeholder group. These hui were held either in Hamilton, Aotearoa (where the majority of the team were based), or in each community. Overall, in each community there were one to two preliminary hui carried out during the initial conception of the project (prior to receiving funding), and another one to two hui following the receipt of funding.

Following these initial hui, SC was responsible for maintaining the relationship with stakeholders from each community and coordinating the organisation of a community hui in each location. SC worked with stakeholders to recruit participants for each hui, including designing recruitment flyers and organising dates, times, venues, kai (food), and koha (contributions/gifts) for hui. Such tasks involved repeated interactions between SC and each stakeholder over several months until all hui details were finalized. Flyers were circulated by the stakeholders. Some stakeholders also devised additional initiatives that they thought would work best in their communities to publicise the hui. For instance, the stakeholder in Community A created a 
Facebook event linked to a local iwi (tribe) community page to recruit participants, and a stakeholder in Community $\mathrm{C}$ included the recruitment flyer and information about the hui in a regular community newsletter.

It is important to note that had SC acted on her own without the sanctioned support of initial stakeholders, the community members would likely not have had the opportunity to know and trust the research team sufficiently to want to attend the hui. The co-design methodology supported each stakeholder, who vouched for the team members and the process of the project, to personally recruit participants within their communities and to ensure their attendance. In all recruitment materials the name of the stakeholder and/or the organisation they worked with was prominently displayed. The significance of establishing such a link was twofold. First, it was vital that the stakeholders trusted the team in order for their communities to also then trust the team. Therein lay the significance of the initial hui between the team and each stakeholder. This is a key consideration when working with Māori communities, as well as for Māori researchers, where the stakeholders' reputation is linked to that of the team. Second, establishing relationships was a way of acknowledging and appreciating the time, help, and support provided by each stakeholder to the team. Overall, taking time to build trust was a vital part of the research process. Mistrust of research among Māori is common due to a history of racism, negative stereotyping, mistreatment, and oppression that resulted from Aotearoa's colonial past, and the role of Western "research" approaches in that past (Cormack et al., 2013; Harris et al., 2015; Harris et al., 2012; Oetzel et al., 2017).

\section{Other Communities}

The process of approaching and establishing trust relationships with Communities A to D was relatively straightforward. However, there was also a community (Community E) that was approached and was not willing to be involved with the project. An initial introductory hui was organised with Community E, and the team travelled to attend. Following whakawhanaungatanga and an initial overview of the project and its aims, it became apparent that those present were very cautious about the project and the effect it would have on their community. By the end of the hui, it was clear that Community E was reluctant to proceed with the project. A kaupapa Māori approach respects the rights of individuals and groups to choose (either directly or indirectly) that a project or process is not right for them; we therefore did not progress with Community E from this point.

Conversely, the team encountered Community $\mathrm{F}$, who had heard about the project from Community A and requested that a hui be organised in their locality. A community hui was planned with the help of two Māori health professionals and was well attended by community members. However, based on the discussion with whānau at this hui, it became clear that for Community $\mathrm{F}$, the barriers to early diagnosis were predominantly related to secondary and/or specialist care. Community $\mathrm{F}$ had an active primary care team, who played a strong advocacy role to ensure that their patients got the best treatment and support possible. Community $\mathrm{F}$ had strong enablers in place for early diagnosis of lung cancer, and the team did not want to change or affect what was already being successfully undertaken. The team did not proceed on to the co-design 
phase in Community F. Rather, the team agreed to revisit Community F and update them on how the project was progressing, and to discuss the barriers experienced by other communities and the interventions that were co-designed.

\section{The Community Hui}

In the four communities the team worked with, hui were carried out at either local marae (traditional meeting places) or meeting rooms organised by the stakeholders. The team members who attended all the community hui were JK, SC, AR, RL, and Kaumatua Hemi Curtis (HC). The stakeholders had organised attendance for each hui, as well as the seating arrangements and kai. At this stage, the team only had to arrive at each location and commence the hui. Figure 1 shows a sign at the entrance of the meeting room where the hui with Community A occurred, set up by the stakeholder in that community. The team tailored their approach according to where hui were held (e.g., on a marae versus in a meeting room). In particular, hui that were held on marae involved an adherence to tikanga, such as commencing with a po whiri (ritual of encounter). Consequently, the team wore appropriate attire as dictated by local tikanga, they prepared waiata (songs) for these hui, and HC (as Kaumātua) led the team onto the marae (see Durie [2007] for in-depth discussions of pōwhiri/marae processes). The community hui carried out in meeting rooms were less formal. For all hui, irrespective of the space within which they occurred, the proceedings began with a karakia (prayer) by $\mathrm{HC}$ or a representative of the community, and whakawhanaungatanga with each team member introducing themselves with a mihi (recitation of one's family origins), often in te reo (the Māori language). The use of te reo here was important both due to it being consistent with our kaupapa Māori approach, and also as a way of respecting tikanga of the communities we were working with.

\section{Figure 1}

Sign at Entry of a Meeting Room for Hui with Community A

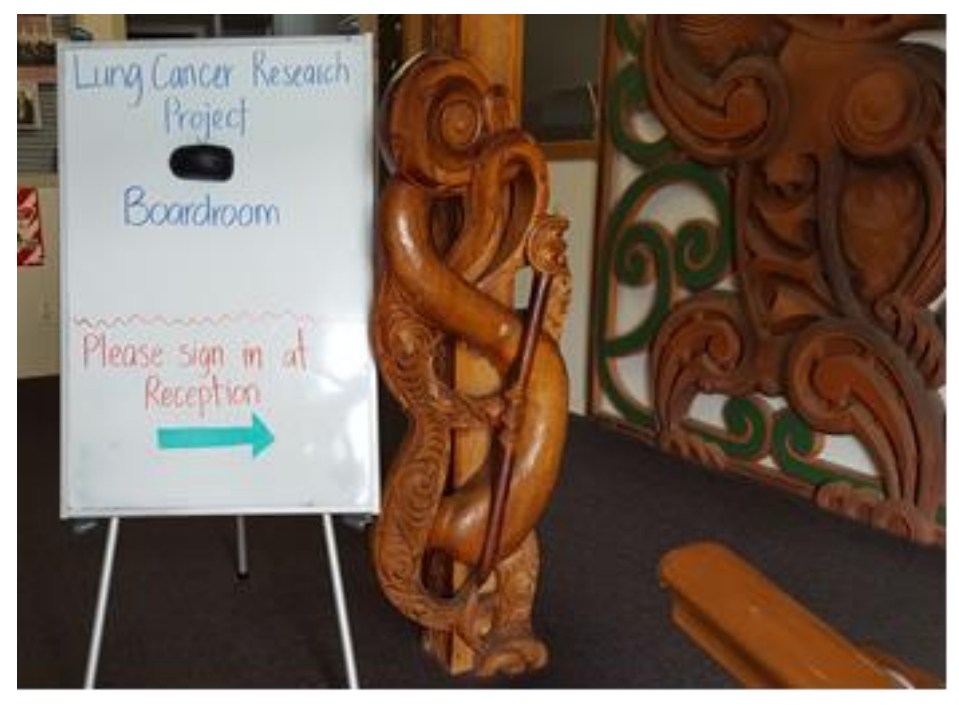

V OLUME 16 , IS S UE 2, $2021 \bullet 199$ 
Following whakawhanaungatanga, JK explained the aims of Hā Ora, what we wanted to discuss with the community, and the process we proposed to follow (Figure 2 depicts an image of $\mathrm{HC}, \mathrm{JK}$, and RL at a community hui). One of the general practitioners in the team (RL or RK) provided a brief overview of lung cancer, including incidence, mortality, and survival rates, and acted as "medical liaison." RL and RK had differing styles of engagement with hui participants. RL is English, a senior academic, and an experienced medical practitioner who has worked in rural general practice in Aotearoa over many years. RL contributed specialist knowledge in medicine. RK is Māori, a general practitioner, and an emerging researcher. RK acted as a whānau member navigating the healthcare space when some topics were discussed and also as medical liaison. The roles undertaken by RL and RK, particularly their ability to respond to medical questions, were an essential part of the team's engagement with communities. AR and SC's roles involved recording field notes at each hui, including audio recording the discussion, following consent from participants. Accordingly, research data comprised AR and SC's field notes, alongside transcripts of the hui.

\section{Figure 2}

$H C$, $J K$, and RL Facilitating Hui in a Local Marae With Community $D$

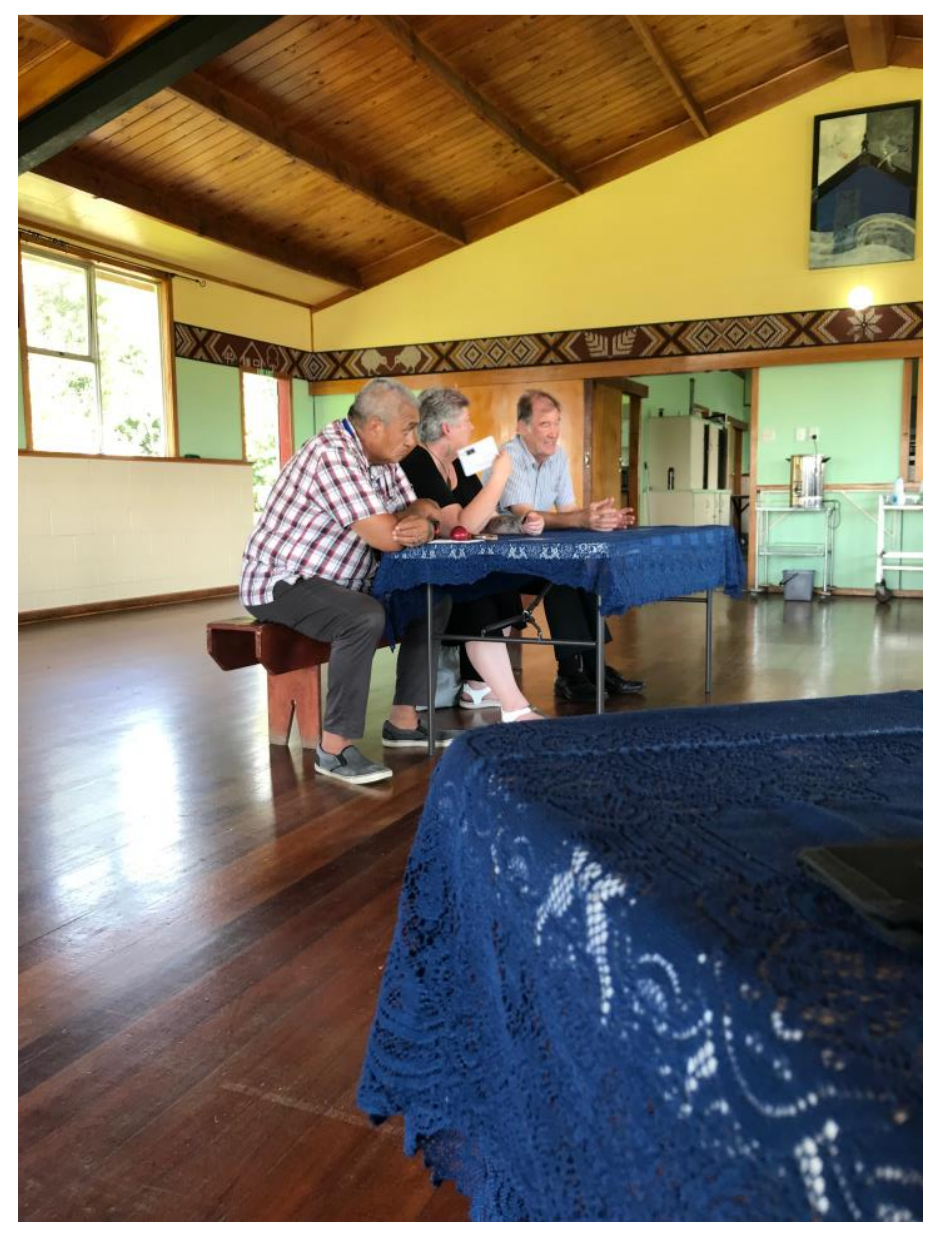

V OLUME 16 , IS S UE 2, $2021 \bullet 200$ 
The team were equipped with a semistructured topic guide for the hui, but this document was seldom used, and topics were brought up by JK only as prompts if required. The aim of each hui was for the communities to direct and lead the conversations with topics centring on their experiences within the healthcare system. The team took a back seat in these conversations, enabling participants to raise what they felt needed to be heard. Noteworthy is that whānau who attended the hui talked about their experiences relating to an array of illnesses, not just lung cancer. They shared their experiences with other types of cancer (e.g., breast cancer, prostate cancer, stomach cancer) and other respiratory conditions (e.g., emphysema, COPD). We realised that many of the barriers and experiences discussed by whānau were also applicable to a lung cancer context, and we agreed that whānau sharing their varied experiences of illness was a strength within our project. More importantly, however, the purpose of the hui was to document whānau kōrero (stories) of navigating the healthcare space, irrespective of whether they were specific to lung cancer or not. Important here was that whānau came and shared their kōrero, which were often very personal. Some even shared kōrero that they had never shared before. Therefore, the team deemed it crucial to value and respect these kōrero, and to treat them with dignity.

Overall, all the communities were curious about what the project hoped to achieve. They were also very interested to know when the team would return to discuss results, to progress with the project, and to generally work with them again. Importantly, the team did not carry out "drive by" visits, or rather, one-off quick engagements with these whānau. Rather, we often held two to three hui with each community, in addition to regular updates and interactions with stakeholders, allowing us to build a working relationship with them, which paved the way for the ensuing codesign process. At the end of each series of community hui, the team invited anyone who was interested to progress on to the next stage of co-designing an intervention.

\section{Timelines, Budgets, and Koha}

The journey from community engagement to the co-design phase of the project was not short, straightforward, or predictable. Timelines and budgets are a key part of project funding, and our research process had a number of factors that impacted on achieving our stated timeline and budget. In particular, our timeline began prior to the project funding being approved, as mentioned previously. Developing trust relationships with key stakeholders is essential from the very beginning of project initiation and design, including when writing project funding proposals, so that partnerships are genuine. Moreover, project teams cannot assume that one hui to introduce the project and to gather participant kōrero is enough to allow communities to decide if they wish to participate in the co-design phase of the project. Rather, the process may involve multiple hui and engagements, to get the communities to a place of co-design. While this could be seen by some researchers and institutions as inefficient or a waste of time (and resources), the additional time taken was an investment in establishing trust and a strong relationship with communities. This in fact is key when working with Māori communities and in 
kaupapa Māori research. Indeed, the additional time taken was an expression of our genuine concern for the community and appreciation of their contribution within the co-design process.

Additionally, no two communities were the same. For instance, in Community A, the team had two initial engagements with the key stakeholder (one where a team member approached the stakeholder in person, and the next where the core team organised a hui via video communication) and two hui with the community prior to being able to organise a co-design hui. Here, while the first community hui was successfully organized and facilitated by the team in partnership with the stakeholder, word had travelled, and the community had requested that the team organise a second hui with them, so that they could bring along more people.

Alternatively, as the process with Community $\mathrm{C}$ involved working alongside three key stakeholders, the team began the engagement with a series of email exchanges and phone calls between the three stakeholders and RL (before and after funding approval) and SC (after funding approval), followed by a kanohi-ki-te-kanohi hui. This resulted in two community hui being organised in Community C. Following the two community hui, word had travelled, and Stakeholder 3 requested that a third hui be organised. Therefore, SC worked with Stakeholder 3 via a series of emails and phone calls to organise the third hui in Community C. Here, while some participants attended all three hui, others only attended one. It was only after these three hui were completed that the team could consider organising a co-design hui with this community.

Accordingly, some key factors that the project budget needed to reflect and incorporate were the cost of multiple community engagements or hui, including the associated costs for kai and koha. Kai, for instance, was a vital part of all our community hui. Hui were always based around morning/afternoon tea and either lunch or dinner. The significance of the kai itself and the timing of when it is brought out is twofold. The first is in its significance as a reciprocal offering to the community, and therefore kai demonstrated our gratitude for their time and effort. More importantly, kai carries with it the ability to whakanoa or remove tapu, the sacredness and restrictions that accompany the formality of a pōwhiri and hui that discuss issues surrounding death and illness. Koha was another important way of acknowledging the participants' time and effort to contribute to this project. The koha provided ranged from fuel vouchers to supermarket gift cards to cash, depending on services available in each community. In most cases we consulted with our stakeholders and asked them what was appropriate to provide as koha. Some forms of koha were easier to legitimise for the project budget and institutional approval than others. For instance, getting institutional approval for fuel vouchers seemed to be relatively easy. In the context of Community C, Stakeholder 2 played a key role in recruiting participants for all three community hui. Therefore, we asked Stakeholder 2 whether she would prefer an individual token of thanks for her time and effort (e.g., a supermarket gift card), or if she would rather receive koha on behalf of her organisation. Stakeholder 2 requested the latter. Accordingly, we sent her organisation a number of fuel vouchers. She responded that these vouchers were immensely helpful over the Christmas period when members of her organisation provided transport assistance to cancer patients travelling to hospital for treatment. 
Conversely, the legitimisation and institutional approval process of koha in the form of cash proved to be more complicated, and lacked cultural understanding on the part of the institution. For instance, when the team attended marae-based hui, tikanga meant that the team presented koha in the form of cash during the pōwhiri. However, institutional conventions relating to the use of research funding do not condone researchers making cash withdrawals from project funding pools. Therefore, the team had to devise an alternative process where one of the team had to withdraw cash from their personal bank accounts to provide koha to marae, and then reimburse themselves with supermarket gift cards purchased from research funds. That said, purchasing supermarket gift cards was also a tedious process involving the completion of a "voucher purchase request form." The form itself was not an issue and completely understandable (and was also the case for purchasing fuel vouchers). However, the complication arose when approval for supermarket gift cards required a condition, statement, or reassurance from the supermarket or the researcher that restricted the purchase of alcohol or cigarettes. The team was not prepared to dictate to participants what they could and could not use koha for.

The point we wish to highlight is that such hurdles imposed by institutional regulations or policies pose ethical and cultural barriers to real-world human research contexts. Funding bodies and institutions need to be more realistic in their approach to research with people and their everyday lives. Accordingly, there needs to be a greater acknowledgement of the cultural and/or ethical requirements of human research, where researchers should not have to devise creative tactics to show respect to and value participant involvement in the research process. Irrespective of such barriers, however, the team presented koha to stakeholders as well as each member of our co-design groups at each co-design hui they attended, as a token of thanks.

\section{Governance and Advisory Groups}

On carrying out a kaupapa Māori, community-engaged research project, yet another key consideration that turned out to be different from the project plan was the structure of our governance and/or advisory groups. Early on in the project, we had already established two governance groups: a Māori Advisory Group (MAG) comprising various leading Māori researchers working in the field of health, as well as an Academic and Clinical Steering Group (ACSG) comprising relevant clinicians and senior academics. These were consistent with the requirements from the funders. The terms of reference for these groups included oversight of the project as a whole and, importantly, providing advice and input into the findings and dissemination of the research. From a clinical, healthcare research point of view, having such higher level co-governance was vital to ensure our findings, outputs, and outcomes were effective in the broader clinical, healthcare setting. However, our formal governance groups did not involve members of the communities we were working with. This is not to say that our stakeholders and members of our co-design groups were not involved at a co-governance capacity in our project. Rather, despite not being considered "advisers" or members of a formal "governance group," our interactions with community groups ensured that they had a say in the 
research process. Therefore, our community groups acted as governors of the research process, in conjunction with the formal MAG and ACSG.

Regular meetings with our official governance groups (the MAG and ACSG) served a different function, and occupied a different space to that of our unofficial community governors. As such, having the MAG and ACSGs in the way we did had a korowai (traditional cloak) effect for our community groups. Specifically, when worn, a korowai can enhance the mana (pride and status) of the wider whānau who own it. Thus, we found ourselves taking information (findings, points of discussion, issues raised, etc.) from community groups and presenting them to the MAG and ACSG as evidence, which then "legitimised" such information for the purpose of an institution-led research project. Here, we do not aim to imply that Māori communities need to prove the legitimacy or validity of their whakaaro (thoughts/opinions) - a constant reality within a Pākehā world. Rather, having the community's views validated in this manner allowed us to ensure that we brought their best interests, thoughts, and views to the fore throughout the project. This also demonstrated a more community-driven approach, rather than a top-down authoritative approach.

\section{Initiating the Co-design Process}

The co-design phase of Hā Ora involved repeated interactions between members of the team and co-design groups. AR took the lead with the co-design phase in Communities A and C, whereas JK took the lead with Communities B and D. SC coordinated the co-design interactions alongside the design of interventions for all four communities.

During the conception of the project, the team envisioned that communities would suggest similar interventions that they would co-design with the team. However, the reality of the project was that the four communities (co)produced four different ideas for interventions. The interventions included a Hā Ora website, a health-related media campaign, a kaiawhina (healthcare advocate) training programme, and a "pou pupuru ōranga" (healthcare advocate/navigator) role. While each of these initiatives took vastly different forms, it was clear that their content or key rationale held a common, linking thread involving messages of health literacy. Thus, all the interventions included an education element, to promote awareness of lung health and respiratory symptoms and illnesses including lung cancer (focused on patients, whānau, kaiawhina, or other healthcare mentors or professionals).

\section{Lessons Learned}

This article discusses the methodological processes and intricacies of a communitydriven co-design project aimed at improving early diagnosis of lung cancer for rural Māori communities. Our research process highlights three key issues that require us to revisit the issue of community consultation versus community-driven engagement as being the basis of codesign, mentioned in the introduction. First, we highlight the importance of the process of coproduction when devising an intervention for a specific community. Second, we advocate for 
flexibility in the research process. Finally, we problematise the idea of generalising interventions at a national level.

To focus on the first issue, we emphasise that, in order to carry out a successful co-design process in which the community is truly involved and thus also ensures greater uptake of the resulting intervention, community-driven engagement is vital. Researchers need to ensure they co-produce the intervention with their communities and/or key stakeholders so that the intervention reflects the realities of the communities involved. Moreover, through this article, we attempt to provide a snapshot of what real community-driven engagement can look like. As such, we demonstrate that this is often a complex process that is almost certainly never straightforward or predictable (cf. Kidd \& Edwards, 2016). Community engagement involves walking away if communities indicate that they do not want to work with you. It involves lengthy, often unpredictable time frames, and the formulation of workarounds for any institutional hurdle that may present itself. Community engagement involves taking information and ideas back to the communities and getting their feedback on how the process was for them. Researchers should be wary of laying down their expectations of what communities need to do for them. Rather, as was demonstrated in our project, the communities were encouraged to drive or lead us. This was clear, for instance, in the fact that despite the key focus of our project being early detection of lung cancer, whānau discussed not only lung cancer at the hui, but all cancers and potentially other respiratory conditions as well.

Accordingly, flexibility in a research process in relation to participant engagement, time frames, and expectations for what we gathered as data was a crucial component of our research process specifically, but also relevant to co-design and kaupapa Māori research overall. Within such a research context, a key priority should be respecting and valuing the contribution of the participants. Community-engaged research should prioritise enhancing the mana of the whanau we are working with (cf. Te Morenga et al., 2018). As such, our research experience has led us to ask the question: How do you get the health message about cancer to at-risk, rural communities? The answer: you don't. You engage with them, and you work with them to construct the message.

Finally, researchers, health service providers, and/or governments tend to assume a "onesize-fits-all" approach to healthcare interventions, especially for Māori. It is assumed that if a pilot can work in one locality, it can be generalisable and thus successfully implemented at a national level. However, our research demonstrates why such assumptions are problematic and often lead to unsatisfactory uptake of such interventions. Rather, the four communities clearly illustrate that what works for one locality may not work at all for another. This is clear from the diverse dynamics that characterised the communities we worked with in terms of the stakeholders we engaged with, the kawa (protocols) of each location, and the different interventions they devised.

Overall, this article encourages researchers and institutions to rethink who our research is for. Who will it benefit? How we can ensure that research agendas reflect the goals of communities, rather than those of a researcher or their institution? 


\section{References}

Bate, P., \& Robert, G. (2007). Bringing user experience to healthcare improvement: The concepts, methods and practices of experience-based design. Radcliffe Publishing.

Boyd, H., McKernon, S., Mullin, B., \& Old, A. (2012). Improving healthcare through the use of co-design. New Zealand Medical Journal, 125(1357), 76-87. https://www.nzma.org.nz/journal-articles/improving-healthcare-through-the-use-of-codesign

Cormack, D. M., Harris, R. B., \& Stanley, J. (2013). Investigating the relationship between socially-assigned ethnicity, racial discrimination and health advantage in New Zealand. PLOS ONE, 8(12), e84039. https://doi.org/10.1371/journal.pone.0084039

Durie, M. (2007). Counselling Māori: Marae encounters as a basis for understanding and building relationships. New Zealand Journal of Counselling, 27(1). https://www.nzac.org.nz/assets/Uploads/Journals/1.-Counselling-Maori.pdf

Harris, R., Cormack, D., Stanley, J., \& Rameka, R. (2015). Investigating the relationship between ethnic consciousness, racial discrimination and self-rated health in New Zealand. PLOS ONE, 10(2), e0117343. https://doi.org/10.1371/journal.pone.0117343

Harris, R., Cormack, D., Tobias, M., Yeh, L.-C., Talamaivao, N., Minster, J., \& Timutimu, R. (2012). Self-reported experience of racial discrimination and health care use in New Zealand: Results from the 2006/07 New Zealand Health Survey. American Journal of Public Health, 102(5), 1012-1019. https://doi.org/10.2105/AJPH.2011.300626

Kidd, J., \& Edwards, G. (2016). Doing it together: a story from the co-production field. Qualitative Research Journal, 16(3), 274-287. https://doi.org/10.1108/QRJ-07-20150059

Oetzel, J., Scott, N., Hudson, M., Masters-Awatere, B., Rarer, M., Foote, J., Beaton, A., \& Ehau, T. (2017). Implementation framework for chronic disease intervention effectiveness in Māori and other Indigenous communities. Globalization and Health, 13, Article 69. https://doi.org/10.1186/s12992-017-0295-8

Oetzel, J. G., Villegas, M., Zenone, H., White Hat, E. R., Wallerstein, N., \& Duran, B. (2015). Enhancing stewardship of community-engaged research through governance. American Journal of Public Health, 105(6), 1161-1167. https://doi.org/10.2105/AJPH.2014.302457

Pihama, L. (2017). Kaupapa Māori theory: Transforming theory in Aotearoa. In L. Pihama, S.-J. Tiakiwai, \& K. Southey (Eds.), Kaupapa rangahau: A reader (2nd ed., pp. 6-15). Te Kotahi Research Institute.

Pitama, S., Wells, J. E., Faatoese, A., Tikao-Mason, K., Robertson, P., Huria, T., Gillies, T., Doughty, R., Whalley, G., Troughton, R., Sheerin, I., Richards, M., \& Cameron, V. A. (2011). A Kaupapa Māori approach to a community cohort study of heart disease in New Zealand. Australian and New Zealand Journal of Public Health, 35(3), 249-255. https://doi.org/10.1111/j.1753-6405.2011.00702.x

Rodgers, P. A. (2018). Co-designing with people living with dementia. CoDesign, 14(3), 188 202. https://doi.org/10.1080/15710882.2017.1282527

Smith, L. T. (1999). Decolonizing methodologies: Research and Indigenous Peoples. Zed Books. 
Te Morenga L., Pekepo, C., Corrigan, C., Matoe, L., Mules, R., Goodwin, D., Dymus, J., Tunks, M., Grey, J., Humphrey, G., Jull, A., Whittaker, R., Verbiest, M., Firestone, R., \& Ni Mhurchu, C. (2018). Co-designing an mHealth tool in the New Zealand Māori community with a "Kaupapa Māori” approach. AlterNative: An International Journal of Indigenous Peoples, 14(1), 90-99. https://doi.org/10.1177/1177180117753169

Tipene-Leach, D. C., Coppell, K. J., Abel, S., Pāhau, H. L. R., Ehau, T., \& Mann, J. I. (2013). Ngāti and healthy: Translating diabetes prevention evidence into community action. Ethnicity \& Health, 18(4), 402-414. https://doi.org/10.1080/13557858.2012.754406

Waitangi Tribunal. (2019). Hauora: Report on Stage One of the Health Services and Outcomes Kaupapa Inquiry. https://forms.justice.govt.nz/search/Documents/WT/wt_DOC_152801817/Hauora\%20W. pdf 